\title{
Estimation of Direct Solar Radiation of Chad
}

\author{
Mahamat Hassane Babikir ${ }^{*}$, Donatien Njomo', Mahmoud Y. Khayal2, Hermann D. Temene', \\ Djampou T. Joel ${ }^{1}$
}

${ }^{1}$ Environmental Energy Technologies Laboratory (EETL) Department of Physics, Faculty of Sciences, University of Yaoundé I, Yaoundé, Cameroon

${ }^{2}$ National Center of Research and Development (NCRD), University of N'Djamena, N'Djamena, Chad

Email: ${ }^{*}$ hassanemahamat6@gmail.com

How to cite this paper: Hassane Babikir, M., Njomo, D., Khayal, M.Y., Temene, H.D. and Joel, D.T. (2018) Estimation of Direct Solar Radiation of Chad. Energy and Power Engineering, 10, 212-225. https://doi.org/10.4236/epe.2018.105015

Received: March 16, 2018

Accepted: May 22, 2018

Published: May 25, 2018

Copyright $\odot 2018$ by authors and Scientific Research Publishing Inc. This work is licensed under the Creative Commons Attribution International License (CC BY 4.0).

http://creativecommons.org/licenses/by/4.0/

\begin{abstract}
The aim of this paper is to estimate the direct solar radiation on a horizontal plane in five regions of Chad using the Liu and Jordan's model in view of the installation of a thermo-solar power plant. For this purpose, the HelioClim-3 Data Base of Solar Irradiance V5's is used. All the results presented in this paper were obtained using Microsoft Excel software 2015. These results show that compared to the other regions considered for this study, the direct solar radiation on a horizontal plane in Moundou is less.
\end{abstract}

\section{Keywords}

Direct Solar Radiation, Inclined Plane, Excel, HelioClim-3, Chad

\section{Introduction}

The development of a good number of human activities in a region is closely linked to the knowledge of its solar climate. For example, in the field of Agronomy, an accurate understanding the phenomenon of evapotranspiration is appropriate in the evaluation of plants' water requirements. In the field of Meteorology, it is very indispensable for climatic forecasts. Another example is the sizing of any solar energy conversion system designed to operate in a given region and of which it is essential to predict the solar radiation.

The solar radiation is generally composed of two fractions: one being the direct solar radiation corresponding to the radiation passing through the atmosphere without any deviation, and the other called diffuse solar radiation corresponding to the radiation coming from all the other directions.

In the industrial applications of solar energy, the knowledge of direct solar radiation is solely relevant. Unfortunately, the scarcity of radiometric stations in certain countries of the world, such as Chad, makes it difficult to adequately 
study the energy and meteorological components of the solar energy. This solar radiation also depends on geographical factors (longitude, latitude, altitude) and meteorological conditions (atmospheric disturbance, rhythm of the seasons in the year, etc.) [1]. This is the reason why it is very necessary to apply a calculation model to estimate this radiation.

The calculation of the solar radiation has been a major concern to many researchers, as summarized in [2] [3]. Numerous formulas have been proposed by different researchers to estimate direct solar radiation from global radiation [4].

However, in the case of Chad, a country in Sub-Saharan Africa (Figure 1), in addition to being characterized by a poorly known solar climate due to the absence of meteorological stations, has not yet to our knowledge been subjected to any study of this kind. In order to be able to model direct solar radiation using the Liu-Jordan method, the meteorological data used here, are derived from the HelioClim-3 data base developed by MINES Paris Tech-ARMINES (which can be consulted online at http://www.soda-is.com/). The data base provides a global horizontal irradiation estimation based on satellite data which takes into account, for a given location, the relative Earth-Sun geometry variations.

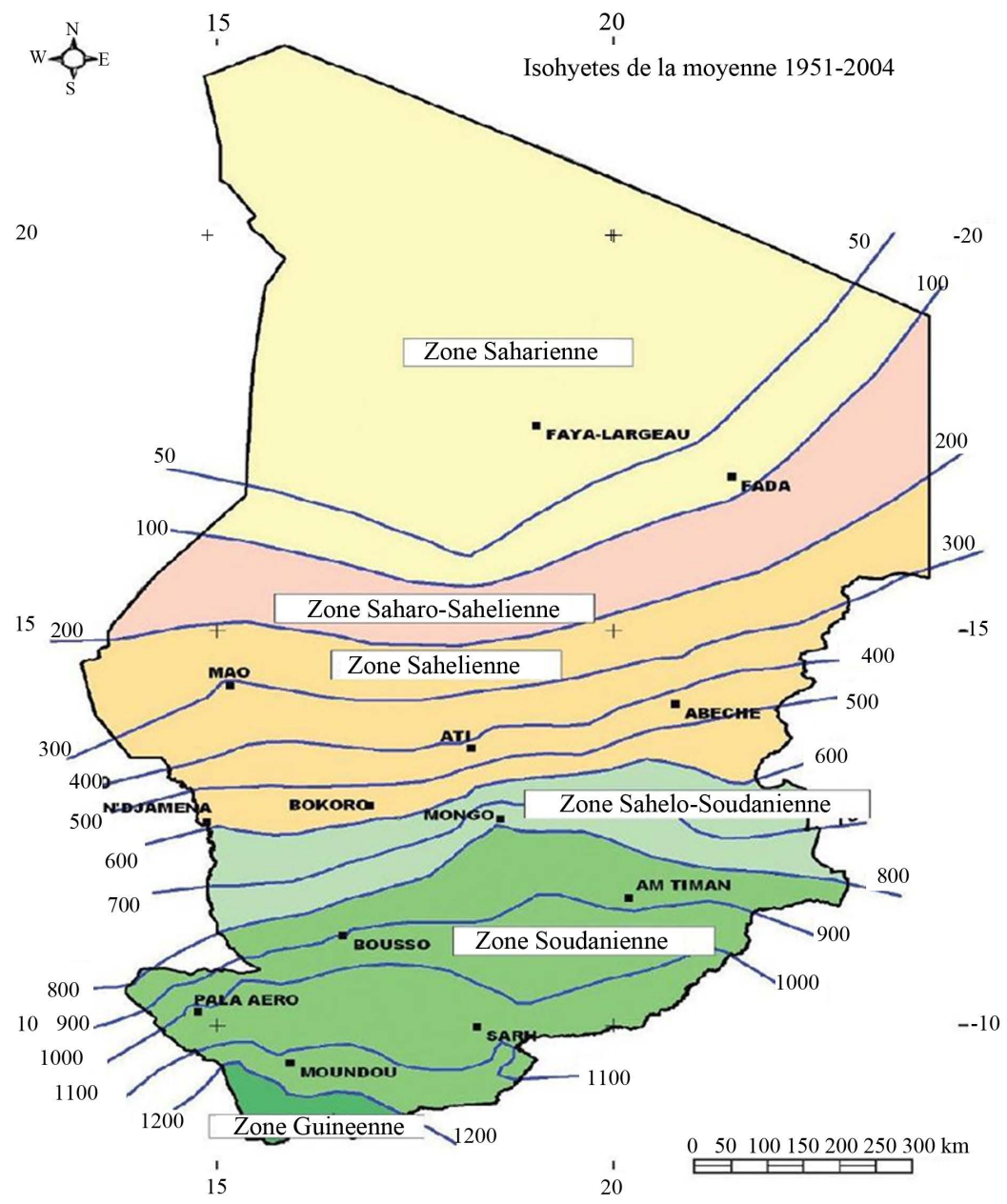

Figure 1. Climatic chart of Chad [30]. 
The period considered goes from the 01 of January to the 31 December 2015. Images of geostationary meteorological satellites are processed to produce estimates of solar radiation at the surface [5]. The measurements taken by the satellite will probably offer the advantage of being more accurate and representative of the conditions prevailing between the ground stations than others, predicted by interpolation [6]. Some authors use satellite data and data from the network of ground stations to build a map of the solar irradiation of a locality [7]. The sites of Chad, for which we have had the data, are: Abeche, Aozou, Faya Largeau, Moundou and N'Djamena. That's why it is on these sites that our study will be applied. Table 1 gives the geographical coordinates of each site.

\section{Angular Calculations and Schedules in Solar Geometry}

Direct solar radiation on a surface is computed from the geometric position of the sun vector with according to the surface. It begins with the calculation of the position of the sun in space and the calculation of azimuth angles and elevation of the sun. These angles make possible the calculation of the angles of incidence on the studied surface [8].

\subsection{The Solar Inclination}

The declination $\delta$ (Figure 2) is the angle formed by the direction of the Sun with the celestial equatorial plane. It varies during the year between $-23.45^{\circ}$ and + $23.45^{\circ}$. This inclination has effect on the presence of various seasons and also the cause of the longer or shorter hours of sunshine during the seasons. The solar declination of any given day of the year is given by the following expression [9] [10] [11] [12]:

$$
\delta=23.45 \sin \left(\frac{360(n-24)}{365}\right)
$$

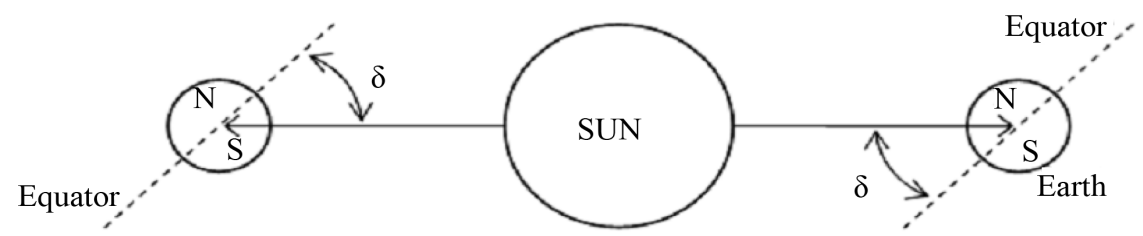

Figure 2. Variation in declination due to earth's orbit [14].

Table 1. Geographical data for the five sites considered (Source: HelioClim-3).

\begin{tabular}{cccc}
\hline Town & Latitude $\left(^{\circ}\right)$ & Longitude $\left(^{\circ}\right)$ & Altitude $(\mathrm{m})$ \\
\hline Abèche & 13.45 & 20.30 & 545 \\
Aozou & 21.50 & 17.25 & 1046 \\
Faya Largeau & 17.55 & 19.06 & 242 \\
Moundou & 8.34 & 16.04 & 401 \\
N’Djamena & 12.07 & 15.04 & 295
\end{tabular}




\subsection{The Position of the Sun}

For a given place, the position of the sun is spotted at each moment of the day and the year by two different references, this thanks to two planes, a horizontal plane of the place and the equatorial plane of the earth.

\subsubsection{Equatorial Coordinates}

The hour angle $\omega$ is the angle between the meridian plane passing through the centre of the sun and the vertical plane of the site of observation. Thus for a site of longitude $L$, at the time $T L$, the hour angle is calculated using the following equation [13]:

$$
\omega=\frac{2 \pi}{24}\left(T L-N-12\left(\frac{24}{2 \pi}\right) L+E T\right)
$$

$N$ is the time zone number containing the longitude $L$. In Chad, $N=+1$

$E T$ is the equation of time and it is given by the following equation:

$$
\begin{gathered}
E T=9.87 \sin 2 d-7.35 \cos d-1.5 \sin d \\
d=\frac{2 \pi(n+24)}{365}
\end{gathered}
$$

\subsubsection{Horizontal Coordinates}

The sun is located in relation to the horizontal plane of the place of altitude, by two angles, the height and azimuth of the sun.

\section{1) The height of the sun}

The height of the sun is the angle that the direction of the sun makes with its projection on the horizontal plane of the place. The height evolves at each moment of the day according to the following expression [9]:

$$
\sin \alpha_{z}=\cos \delta \cos \varphi \cos \omega+\sin \delta \sin \varphi
$$

The values of the height $\alpha_{z}$ varies between $-90^{\circ}$ and $+90^{\circ}$, and takes the value zero at sunrise and sunset, positive on day and negative at night.

\section{2) Azimuth of the sun}

Azimuth of the sun is defined by the angle of the projection of the direction of solar radiation with the southern direction of the place (Figure 3):

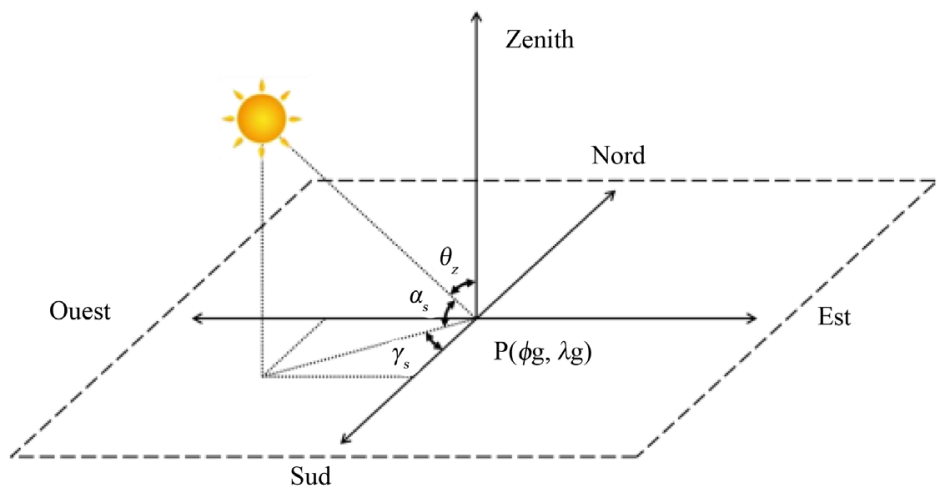

Figure 3. Solar altitude, solar azimuth and zenith angles [31]. 


$$
\cos \theta_{z}=\sin \alpha_{z}
$$

\section{3) The angle of incidence of direct radiation on an inclined plane}

The angle of incidence $\theta$ is the angle formed between the direction of the sun and the normal to the inclined surface of the sensor. The angle of incidence $\theta$ has a primary effect and a direct effect on the amount of sunshine received on the collecting surface. This angle can be determined by the knowledge of the direction cosines of the incident radiation and the normal of the inclined plane in horizontal coordinates of the location. This angle depends on the parameters of the sun position and the angle of inclination of the sensor as shown by the following equation:

$$
\cos \theta=\cos (\varphi-\beta) \cos \delta+\sin (\varphi-\beta) \sin \delta
$$

With $\varphi$ is the latitude of the site and $\beta$ is the angle of inclination (Figure 4).

\section{Calculation of Normal Direct Radiation on a Horizontal Plan}

The reconstitution of the monthly averages per day of normal direct irradiations on a plane is expressed as a function of the global and diffuse irradiations available on this horizontal plane [15]. Several models have been proposed by scientists relating to several sites in the world. Thus, taking into account geographical,

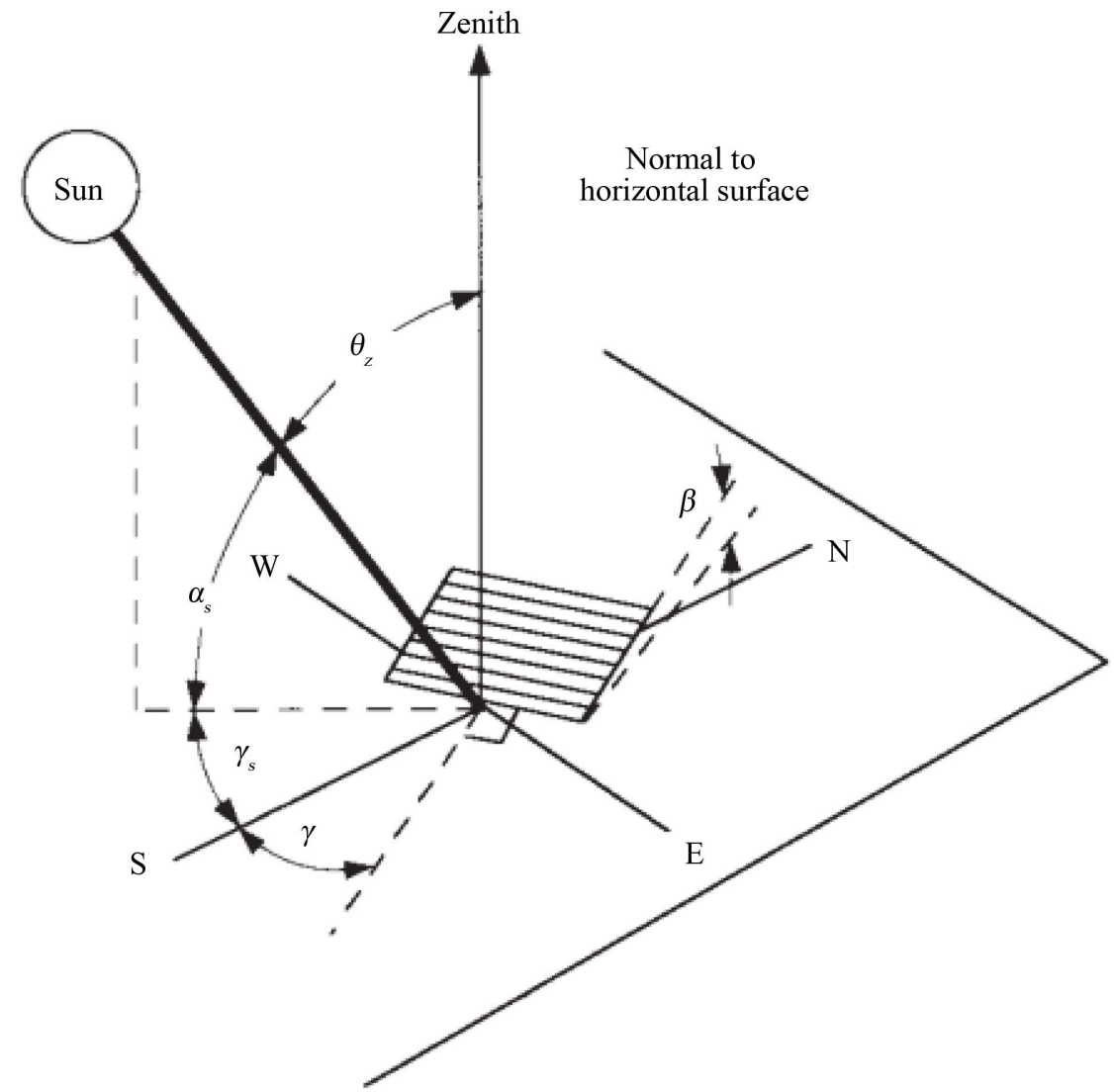

Figure 4. Incident radiation on an inclined surface [32]. 
astronomical and meteorological parameters related to the site. M. Hussain [16], developed a model at several Indian sites. Some authors consider models based on the duration of insolation and relative humidity [17], while others take into account absolute humidity, relative humidity and ambient temperature [18]. There are those [19] who have developed two empirical relationships linking the different meteorological parameters that affect the attenuation of solar radiation, namely: duration of sunshine, relative humidity, maximum temperature, altitude and geographical location. Liu and Jordan [20] consider the monthly averages per day of absolute humidity and duration of sunshine. For the site of Kano, A. Sayigh [21] considered the measurement of insolation duration, maximum and minimum temperatures, mean temperature and specific humidity in northern Nigeria.

For the diffuse component, several contributions have been proposed by several researchers for different sites in the world. Indeed B. Boldbeg [22] develops a formula taking into account the hour angle of the sunrise $\omega_{s}$. In their paper Reddy et al. [23] used time-based measurements on four US stations, global and diffuse irradiations to develop a model depending on the season.

The global solar radiation on a horizontal surface $I_{G h}$ is the sum of horizontal direct solar radiation and horizontal diffuse irradiation. Thus, in order to calculate the direct irradiation component on a horizontal plane, the diffuse irradiation is subtracted from the total irradiation:

$$
I_{D h}=I_{G h}-I_{d h}
$$

The global solar radiation received by an inclined surface consists of beam, diffuse, and reflected radiation. The reflected solar radiation here is the radiation reflected from the surrounding ground. Different models for estimating the global solar radiation on inclined surfaces had been proposed and evaluated. Most of the models presented in the literature proved to give good results. The majority of these models use similar terms for the beam and reflected radiation but differ in the method of calculating the diffuse solar radiation component. The general equation of the global hourly solar radiation energy incident on an inclined surface is given by [24]:

$$
I_{G}=R_{D h} I_{D h}+\rho\left(1-\frac{\cos \beta}{2}\right) I_{d h}+\left(1+\frac{\cos \beta}{2}\right) I_{d h}
$$

Among the methods available for prediction of radiation fluxes on tilted surfaces is the method of (Liu and Jordan 1963). This is a simple isotropic model that had been tested by many investigators and found to give good results. In this method the beam radiation on the tilted surface is given by [25]:

$$
I_{D I}=\left(I_{G h}-I_{d h}\right) \frac{\cos \theta}{\cos \theta_{z}}
$$

$I_{D I}:$ is the beam radiation on the titled surface

$I_{G h}$ : is the total radiation on the horizontal surface

$I_{d h}:$ is the diffused radiation 
$R_{D h}$ : is the hourly geometric factor defined by [26]:

$$
R_{D h}=\frac{\cos \theta}{\cos \theta_{z}}
$$

where $\theta_{z}$ is the solar zenith angle.

\section{Results}

This part presents the results of values of the direct monthly irradiation per hour available on the horizontal plane for different regions of Chad (Figure 5 and Figure 6). Figure 7 and Figure 8 show the results obtained on an inclined plane assuming that the surface is oriented to the south with an inclination of $15^{\circ}$.

\section{Interpretation}

We have presented the potential of average monthly values per day of the direct normal solar irradiance on a horizontal and inclined plane in Chad by an obvious
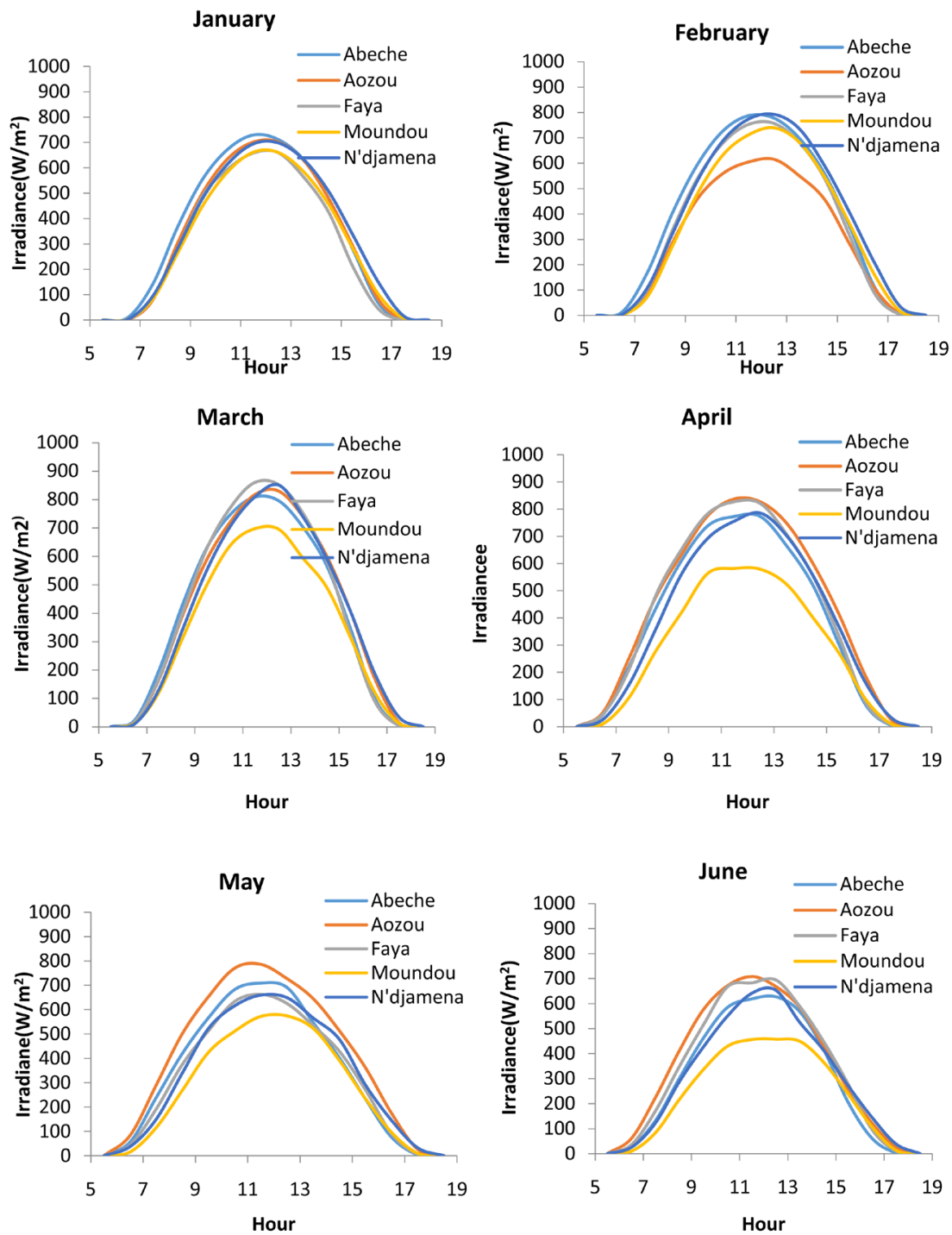

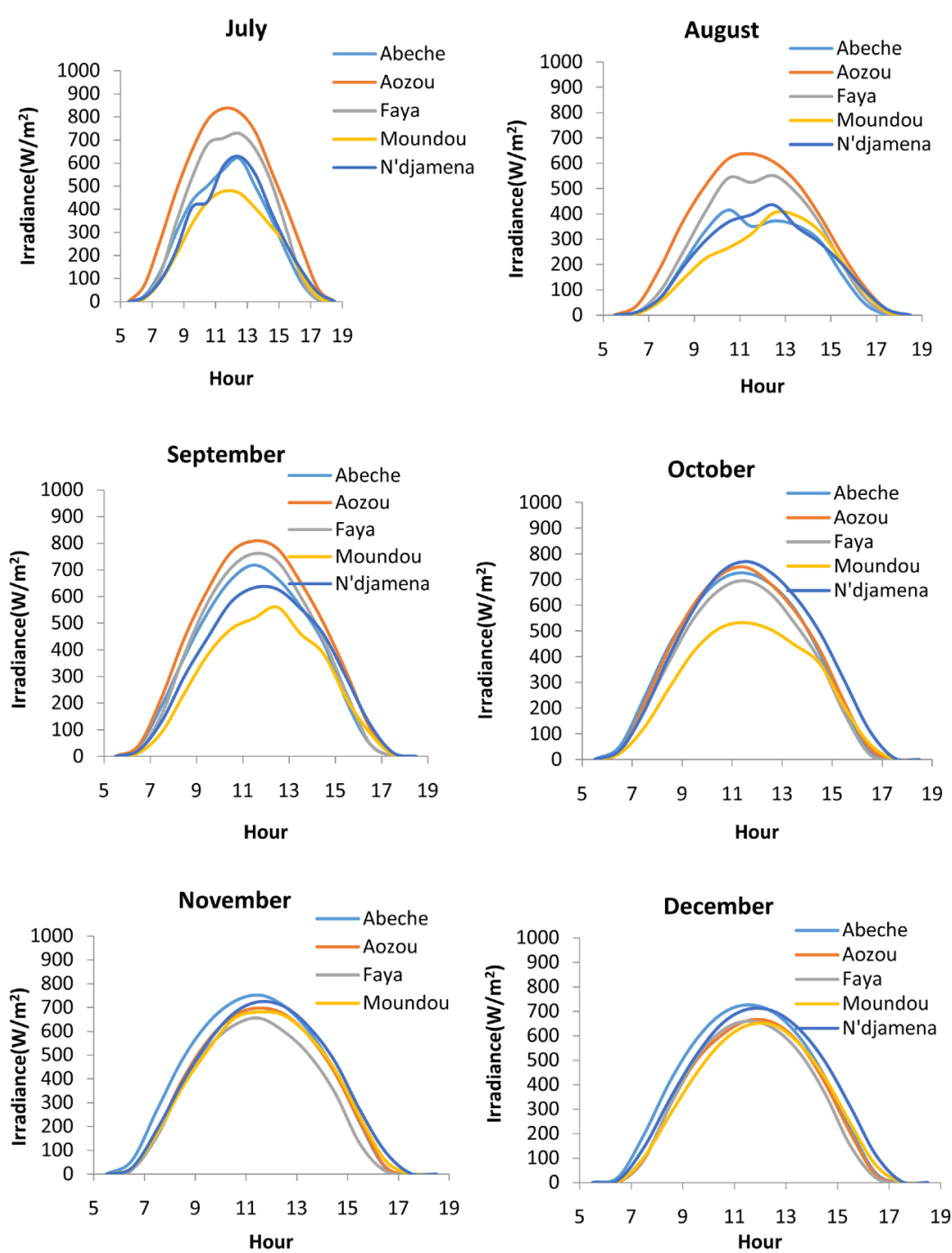

Figure 5. Monthly Mean values by a day of direct solar irradiance on the horizontal surface.

theoretical calculation. Our goal is to establish a relationship for calculating the direct normal solar radiation by using only the geographical coordinates of the place and the number of the day. By analyzing the results obtained so high during the simulation, we see in Figure 6 and Figure 8 that the daily variation received on average for each month of the year of the direct normal solar irradiance from January 1 to December 31, 2015, and depends of the hour of the days.

The amplitude of the maximum annual variation in relation to the value common to the months changes according to the hours throughout the year. It can be seen that from 1 January to 31 December the extreme value of the irradiance is $800 \mathrm{~W} / \mathrm{m}^{2}$. This similarity of the variation of the irradiance is directly related to the hours of the days everywhere one observes that this is between 11 am, $12 \mathrm{pm}$ and $1 \mathrm{pm}$.

Meanwhile, the irradiance received at Moundou is somehow lessened than in 
other cities. This can be explained by the influence of the relief of the said city. Figure 6 and Figure 8 also illustrate the results obtained for the monthly mean
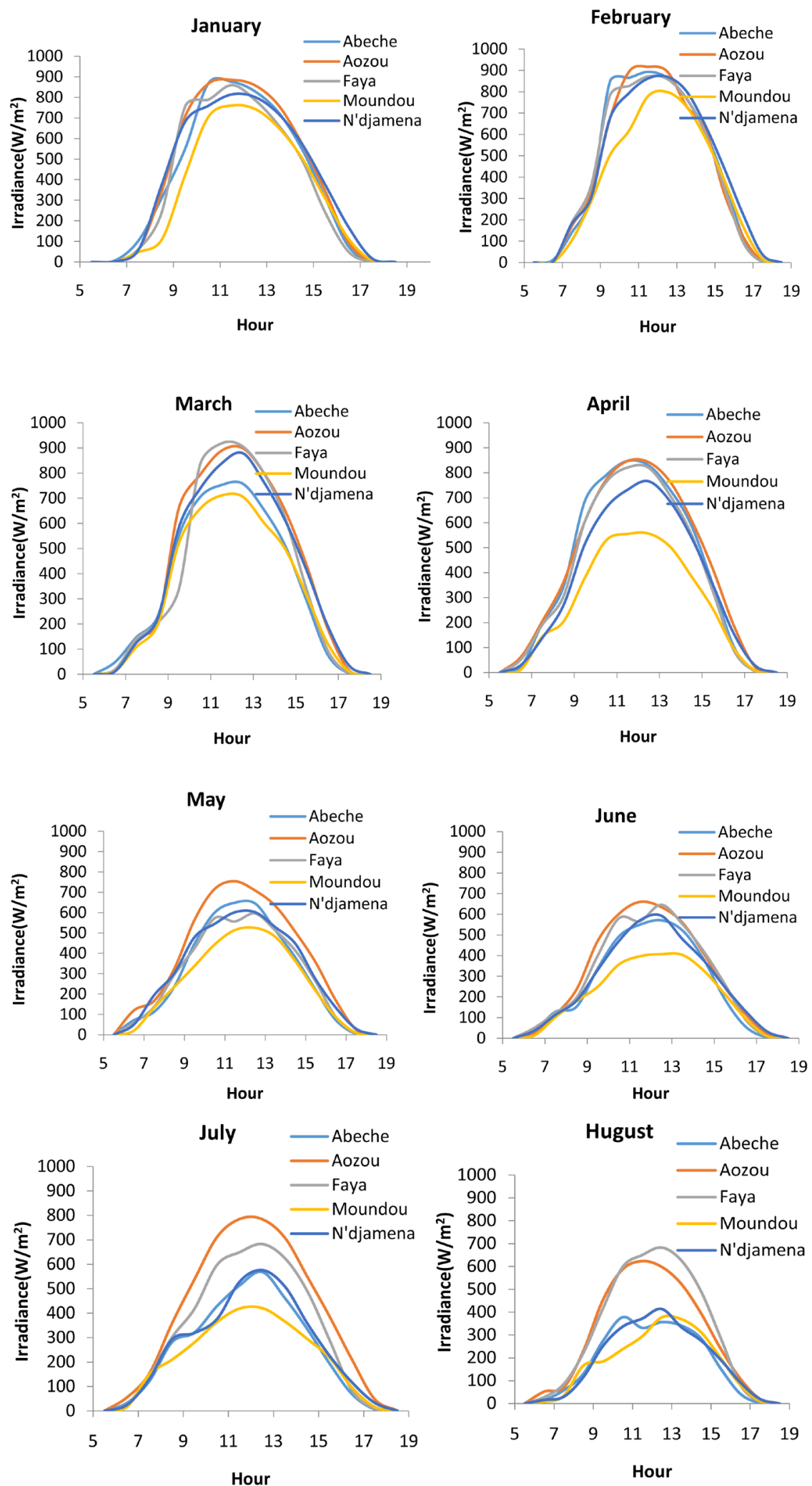

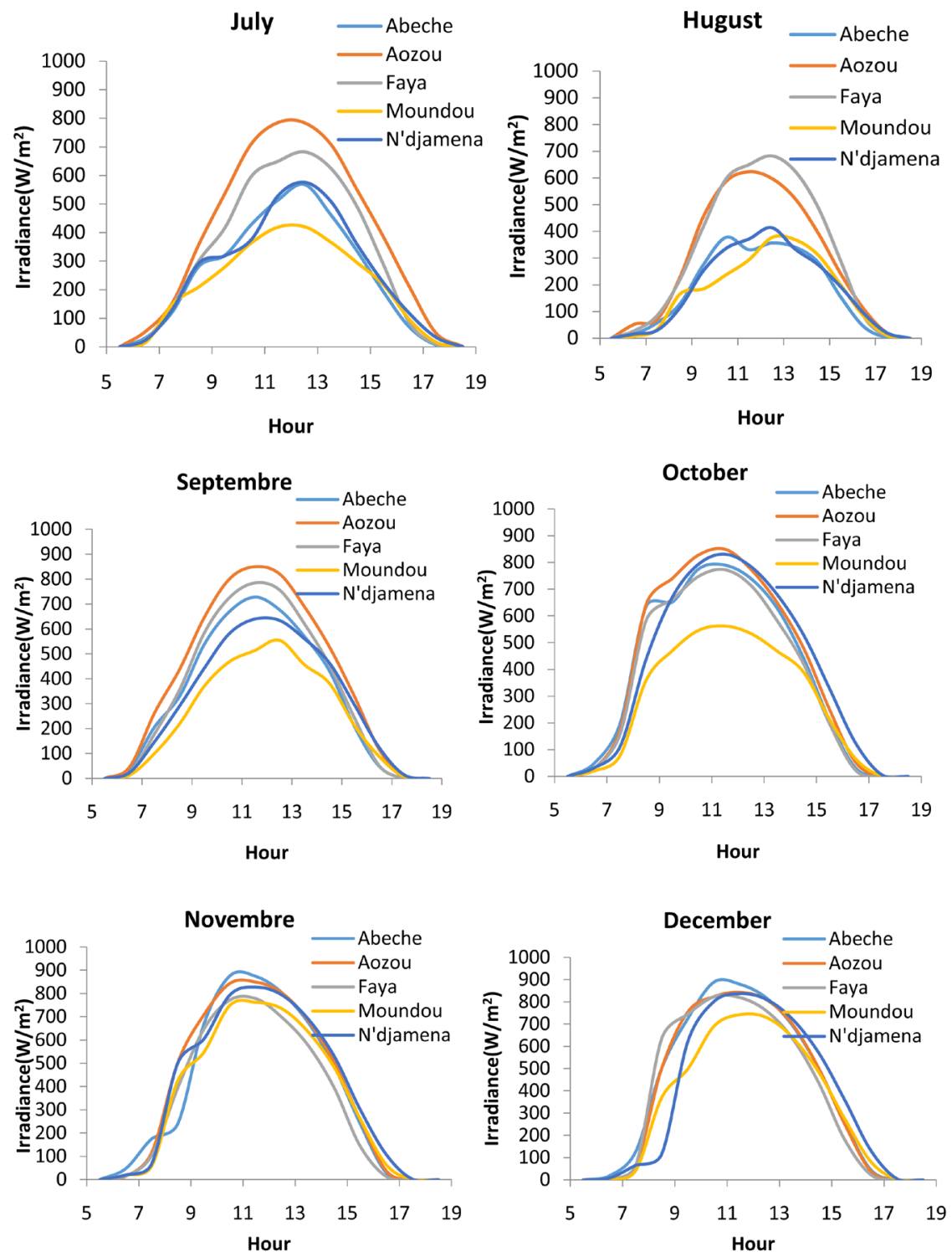

Figure 6. Monthly Mean values by a day of direct solar irradiance on the inclined surface.

hourly average of the direct solar irradiation received on a horizontal and inclined plane, of the 5 sites representing the different regional climates of Chad. It can be seen that all the curves have the same shape, that is to say that in Saharan zones such as the Faya and Aozou region, by observing the histogram, it is also observed that the maximum variation of the monthly average of the irradiation Solar range is between 6 and $6.5 \mathrm{kWh} / \mathrm{m}^{2}$, and the minimum is between 4.5 and $5.5 \mathrm{kWh} / \mathrm{m}^{2}$ throughout the year.

In the Sahelian zone (Abeche, N'djamena) the maximum monthly average of the solar irradiation observed during the months of January to June and from September to December is between 5 and $6 \mathrm{kWh} / \mathrm{m}^{2}$ and the minimum is 4 to 5 $\mathrm{kWh} / \mathrm{m}^{2}$. In this case it is also noted that the maximum from July to September is 3 to $4 \mathrm{kWh} / \mathrm{m}^{2}$ and the minimum is 2.5 to $3 \mathrm{kWh} / \mathrm{m}^{2}$, which varies with the 


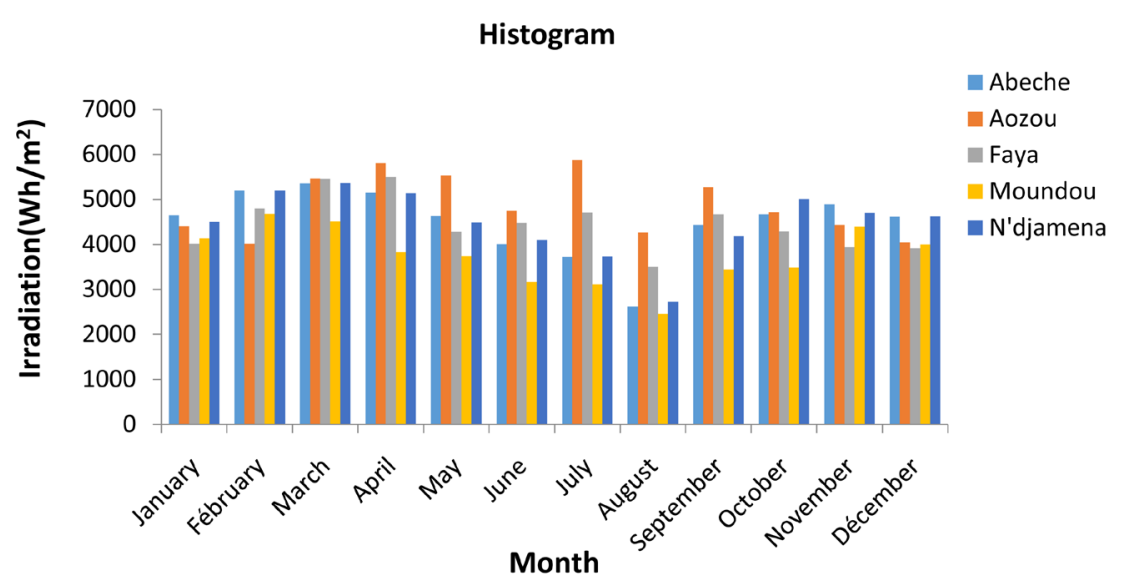

Figure 7. Monthly Mean values of direct solar irradiance on the horizontal surface.

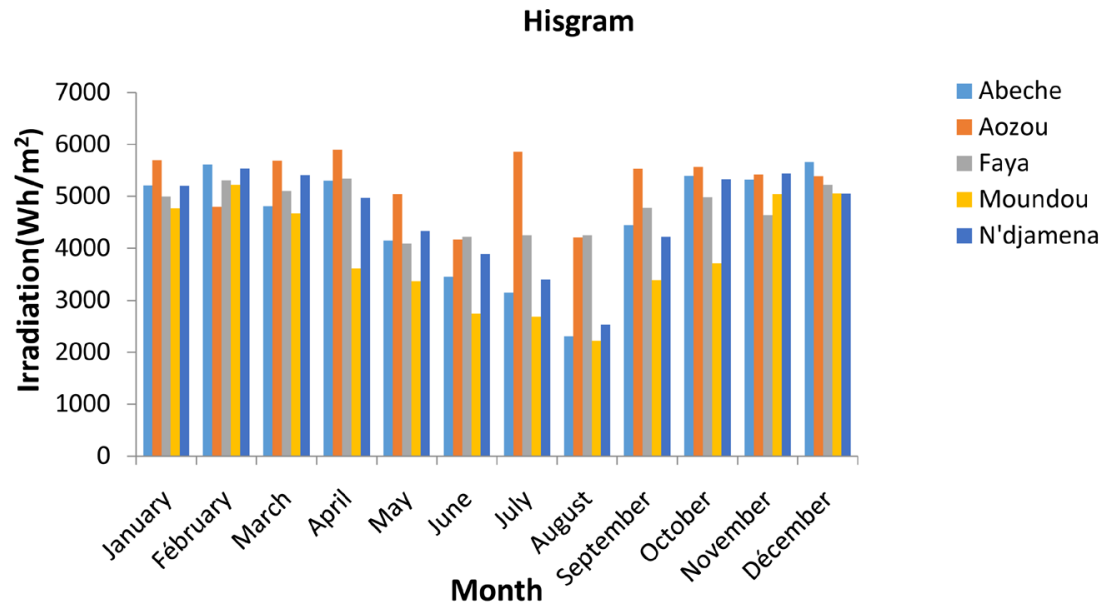

Figure 8. Monthly Mean values of direct solar irradiance on the inclined surface.

local climate impacts.

In the southern part of the country where we have the Sudanese climate, the direct normal solar radiation is somehow disturbed by the climatic risks and also by the long rainy season which sometimes lasts for 5 to 6 months [27] compared to other regions, because the direct solar radiation is much more sensitive when light clouds are passing, even though less visible to the naked eye [28]. This causes the fall of direct solar radiation in this area. We give the results of months during which the irradiation is deficient, whose maximum numerical value of the monthly average of direct normal solar irradiation from April to October is 3 to $4 \mathrm{KWh} / \mathrm{m}^{2}$, and the minimum is 2.3 to $3 \mathrm{KWh} / \mathrm{m}^{2}$.

\section{Conclusion}

In this work, we have modeled the direct normal solar radiation on a horizontal and inclined plane on 5 sites in Chad. The results derived from such a modeling process reveal that the distribution of the solar radiation is nearly the same on the whole territory of the country. Concordantly, the solar radiation in the north 
is higher than the south. The climate diversity of the country is the principal element responsible for the differences explaining the unequal solar radiation distribution between several regions of the country. These results have shown that the whole country have received a more than $2500 \mathrm{KW} / \mathrm{m}^{2}$ direct solar radiation. This shows us that, such an irradiation is a favorable resource for solar concentration plants, with the estimated minimal value of the yearly average of direct solar radiation being $1800 \mathrm{KWh} / \mathrm{m}^{2} /$ Year [29].

\section{References}

[1] Saheb-Koussa, et al. (2006) Reconstitution du rayonnement solaire par ciel clair. Energies Renouvelables, 91-97.

[2] Jakhrani, A.Q., et al. (2012) Estimation of Incident Solar Radiation on Tilted Surface by Different Empirical Models. International Journal of Scientific and Research Publications, 2250-3153, 12 December 2012.

[3] Mesri-Merad, M., et al. (2012) Estimation du rayonnement solaire au sol par des modèles semi-empiriques. Revue des Energies Renouvelables, 15, 451-463.

[4] Perez, R., Ineichen, P., Maxwell, E., Seals, R. and Zelenka, A. (1992) Dynamic Global to Direct Conversion Models. ASHRAE Transactions Research Series, 98, 354-369.

[5] Qu, Z., et al. (2014) Improving HelioClim-3 Estimates of Surface Solar Irradiance Using the McClear Clear-Sky Model and Recent Data Sets on Aerosol Properties. Atmospheric Measurement Techniques, 7, 3927-3933

[6] Gilles, H., et al. (2001) Cartographie par satellite de la ressource énergétique solaire au quebec. 23e symposium canadien sur la télédétection 10e congrès de l'association québécoise de télédétection, quebec.

[7] Zelenka, A., et al. (1999) Effective Accuracy of Satellite-Derived. Theoretical \& Applied Climatology, 62, 199-207.

[8] M'Raoui, A., et al. (2011) Etude statistique du rayonnement solaire à Alger. Energies Renouvelables, 14, 637-648.

[9] Roger, A. and Ventre, M.J. (2003) Photovoltaic Systems Engineering. 2nd Edition, CRC Press.

[10] Kalogirou, S. (2009) Solar Energy Engineering. Academic Press, USA, 59-61.

[11] Duffie, J.A. and William, B.A. (1991) Solar Engineering of Thermal Processes. 2nd Edition, John Wiley \& Sons, Inc., Hoboken.

[12] Sen, Z.K. (2008) Solar Energy Fundamentals and Modeling Techniques. Springer-Verlag, London.

[13] Bernard, R., Menguy, G. and Schwartz, M. (1980) Le Rayonnement Solaire: Conversion Thermique et Application, Technique et Documentation, Paris, 215.

[14] Mayer, D. (1992) Dimensionnement des systèmes photovoltaïques sur batteries. Dans cours de formation, Electricité solaire pour la zone rurales et isolées.

[15] Koussa, M., et al. (2007) Apport énergétique de la poursuite solaire sur deux axes par rapport aux systèmes fixes. Application aux capteurs plans. Energies Renouvelables, 515-537.

[16] Hussai, M. (1984) Estimation of Global and Diffuse Irradiation Form Sunshine Duration and Atmospheric Water. Vapor Content, 33, 217-220.

[17] Garg, H.P. and Garg, S.N. (1983) Prediction of Global Solar Radiation from Bright 
Sunshine Hours and Other Meteorological Data. Energy Conversion and Management, 23, 113-118. https://doi.org/10.1016/0196-8904(83)90070-5

[18] Zeroual, A.M.A. (1996) The Diffuse-Global Correlation: Its Application to Estimating Solar Radiation on Tilted Surface in Marrakesh, Morocco. Renewable Energy, 7, 1-13.

[19] Jacovides, C.P., et al. (1996) On the Diffuse Fraction of Daily and Monthly Global Radiation for the Island of Cyprus. Solar Energy, 56, 565-572.

[20] Liu, B.Y.H. and Jordan, R.C. (1960) The Interrelationship and Characteristic Distribution of Direct, Diffuse and Total Solar Radiation. Solar Energy, 4, 1-19. https://doi.org/10.1016/0038-092X(60)90062-1

[21] Sayigh, A.A.M. (1997) Solar Energy Engineering. Academic Press, London.

[22] Boldbeg, B.W.K. (1978) A Comparison of Some Samples Used to Predict Solar Irradiance on a Horizontal Surface. Solar Energy, 23, 81-83.

[23] Reddy, S.J. (1971) An Empirical Method for the Estimation of Total Solar Radiation. Solar Energy, 13, 289-294.

[24] Liu, Y.H. and Jordan, C. (1963) The Long-Term Average Performance of Flat-Plate Solar-Energy Collectors. Solar Energy, 7, 53-74.

[25] Muneer, T. and Gueymard, C.H.K. (2004) Radiation and Daylight Models. Second Edition, Elsevier Butterworth Heinemann, 13-17.

[26] Heywood, H. (1971) Operating Experience with Solar Water Heating. Journal of the Industrial Heat, 39, 63-69.

[27] Mahamat, D. and Ahmat, A. (2011) Atelier sur les statistique de l'environnement. Ministere de l'environnement et des ressources halieutique, INSEED, Yaounde.

[28] Schwartz, L.M., et al. (1983) Etude du rayonnement solaire global et direct a Carpentras. Revue de Physique Appliquee, 18, 635-644. https://doi.org/10.1051/rphysap:019830018010063500

[29] Breyer, C. (2009) Global Energy Supply Potential of Concentrating. 15-18.

[30] Programme du Système d'Information pour le Développement Rural et l'Aménagement du Territoire (P-SIDRAT). ATLAS Du TCHAD.

[31] Muna, Y.B. (2014) Estimation of Solar Panel Orientation with Different Tilt Angles at Haramaya University. Thesis of Masters of Science in Physics (Environmental Physics), Department of Physics, School of Graduate Studies, Haramaya University, Ethiopia, 102.

[32] Duffie, J.A. and William, B.A. (2013) Solar Engineering of Thermal Processes. Fourth Edition, John Wiley \& Sons, Inc., Hoboken. 


\section{Nomenclature}

$\theta$ Incident angle $\left({ }^{\circ}\right)$

$\theta_{z}$ Solar azimuth $\left({ }^{\circ}\right)$

$\omega$ Hour angle $\left({ }^{\circ}\right)$

$\delta$ Declination $\left(^{\circ}\right)$

$\rho$ Albedo

$h$ Sun's altitude $\left(^{\circ}\right)$

$\beta$ Title angle or Slope angle of the surface $\left({ }^{\circ}\right)$

ET Equation of time (Hour)

LT Legal time (Hour)

$n$ Number of the day (Hour)

$\varphi$ Latitude $\left(^{\circ}\right)$

$R_{D h}$ is the hourly geometric factor

$I_{D I}$ is the beam radiation on the titled surface $\left(\mathrm{W} / \mathrm{m}^{2}\right)$

$I_{G h}$ is the total radiation on the horizontal surface $\left(\mathrm{W} / \mathrm{m}^{2}\right)$

$I_{d h}$ is the diffused radiation $\left(\mathrm{W} / \mathrm{m}^{2}\right)$ 